\title{
Agroecological approach to quality assessment of organic aromatic products
}

\author{
S.L. Belopukhov, M.V. Grigoryeva*, I.I. Dmitrevskaya, A.V. Zhevnerov \\ Russian State Agrarian University RSAU named after K.A. Timiryazev, Moscow, Russia
}

\begin{abstract}
The developed complex scientific-methodical approach to the survey of organic agricultural enterprise was presented in order to confirm the quality of aromatic products of the "Organic" class. The analysis of agrochemical soils indicators was performed for the first time, which were cultivated according to organic technology for eleven years. It was proven that long-term use of organic farming contributes to the preservation and improvement of soil fertility. An elemental biomass analysis of the apical part of lavender plants grown by organic method was carried out, from which the essential oil was then obtained. It was confirmed that the essential oil composition depends on the place of its production and on the soil characteristics on which the plants were grown. The elemental analysis of essential oil showed that there is an intensive carry-over of all major macroand micronutrients from the soil into plants during their growth and development. In the lavender essential oil, there are more than 50 substances that determine its uniqueness. Therefore, to confirm the quality of "Organic" class products, we propose to conduct a comprehensive assessment of all components of the organic production system "soil — plant — products". Thermal analysis, electron microscopy with detectors for energy dispersion analysis, chromatographic analysis, potentiometry, flame photometry and chemical analytical methods were used for the research. Differences in quality indicators of organic essential oil and oil obtained with the traditional farming method were revealed. The study found that the produced lavender oil is a unique quality product grown in an organic way. At present, quality management of agricultural products is possible subject to specialists' availability in the agro-industrial complex with competence in the field of chemical-toxicological and environmental analysis knowing methods to determine the quality and safety of agricultural products, including organic products.
\end{abstract}

\section{Introduction}

Compared to conventional farming, organic farming is characterized by a higher level of agricultural technology. Typically, several integrated farming systems are used depending on products and territories they are produced in. The development of agrotechnologies and elements of technology is normally associated with the use of vital activity's products of

* Corresponding author: marina_gry@inbox.ru 
fungi, bacteria, the use of physiologically active substances, for example, derived from medicinal and aromatic crops, organic poultry manure and other natural organic fertilizers.

Organic agriculture is designed to solve the following tasks:

1. Providing the population with full, safe food.

2. Conservation of biodiversity and ecological well-being of the territory.

3. Optimization of energy resources and minimizing the cost per production unit.

4. Formation of a complete closed cycle for the organic products' production with minimal amount of substances' loss in a closed thermodynamic system of organic agriculture.

Department of Chemistry of the Russian State Agrarian University named after K.A. Timiryazev (RSAU-MAA named after K.A. Timiryazev, Moscow) has been engaged in problems of quality control of agricultural products for more than 10 years with 4 years of joint work with the Union of Organic Agriculture to assess the quality of organic agricultural products in comparison with products grown with traditional technology. The developed educational technologies are used in the training of masters under the program "Agroecological management, chemical-toxicological, microbiological analysis and evaluation of objects of agrosphere" in the direction "Agrochemistry and Agrosoil Science" [1-3], as well as postgraduate students in the discipline "Physico-chemical methods of analysis" and "Thermochemistry of biological objects".

Aromatic crops have long been the object of study in RSAU-MAA named after K.A. Timiryazev. Chemistry of medicinal and aromatic plants has been studied since the foundation of the academy in 1865 and the research is continued today at the Department of Chemistry of our university.

Today the Department of Chemistry of RSAU-MAA named after K.A. Timiryazev continues the traditions of previous generations and cooperates with Nikitskiy Botanical Garden and the All-Russian Research Institute of Medicinal and Aromatic Plants.

Lavender today is one of the most popular on the global market of aromatic plants. Essential oils are obtained from it, which are used in the production of perfumery and cosmetic goods, as well as medicinal products. The lavender oil market is growing at a high rate. The best lavender oil with a characteristic sweet aroma and very high content of linalyl acetate $(50-55 \%)$ is obtained in France. Other lavender oil production centers are Italy, Bulgaria, Crimea, Hungary, England, Australia (Tasmania island) and the United States (Pugent Sound).

The most important task of our time is to provide the population with food products that are balanced in chemical (amino acid, macro- and microcomponent, biochemical, fatty acid, vitamin) composition, environmentally sound, functional, not containing toxicants and thereby improve public health. With the help of organic farming, it is possible to obtain products containing natural metabolites that easily enter metabolism processes in plants, animals, humans. And therefore not causing allergic reactions and other metabolic failures in consumers. Essential oils are components for the cosmetic and pharmaceutical industry, household chemicals and, accordingly, the requirements for their quality are even higher.

Currently, the organic way of growing raw materials for natural cosmetic products is intensively developing. This is due to the fact that after the daily use of synthetic chemistry products, the population began to increasingly manifest allergic reactions. In this regard, consumers began to pay great attention to the composition of cosmetics. The natural cosmetics market in 2018 exceeded $\$ 11.0$ billion and grows further every year [4].

The quality of products ultimately determines the very price that the consumer pays and a higher price for organic products, because in the end, the organic product with a wide natural range of useful physiologically active substances, macro and microcomponents is produced. From organic raw materials, functional products with a certain (or given) chemical composition can then be produced. 
It is very important that organic farming preserves the economy's ecosystem, soil fertility, bio-resources, biodiversity in each particular region. Organic agriculture is primarily involved in the preservation of soil fertility, individual ecosystems, and the ecological wellbeing of the planet as a whole.

In organic farming, as in traditional agriculture, constant monitoring of soil and processes in it is necessary to assess the nutritional elements' balance in the soil, change in humus content, mobile forms of potassium, phosphorus, nitrogen, sulfur, other macro- and microelements, quality, and quantity of soil biota.

Such knowledge is required to develop a digital model for the management of physiological and biochemical processes in organic agriculture to produce high-quality organic products. In the production of organic products, resources of a particular territory (region) are involved, which should eventually lead to obtaining a local brand product. Then, it becomes clear how the essential oil of lavender grown in Crimea differs from, for example, lavender essential oil grown in France, Croatia, Bulgaria or other countries and regions. This requires a digital passport of the organic agriculture's quality reflecting the lay of land. There should be a digital map to understand all the registered differences in the chemical composition of the soil, which determine the chemical composition and quality of products. Thus, the problem of traceability, identification and no distortion of goods is solved.

Such tasks have been solved by us during research carried out in the fields of organic economy growing aromatic plants in the south of Russia - to assess the quality of aromatic products produced in fields cultivated by organic technology for 11 years.

To give an objective assessment of organic products, it is necessary to analyze not only the final product, but also other components of its production system: soil - plant - products (essential oil).

\section{Materials and methods}

The objects of the study were soil, agricultural products of the Limited Liability Company "Efirmaslo" (district of Rusakovka village, Belogorsk district of the Republic of Crimea) [5]. The study of soil and biological samples was carried out using modern physicochemical methods of analysis: gas and liquid chromatography with mass spectrometry, close infrared spectrometry, electron-microscopic analysis with energy dispersion spectrometer, thermography, and a number of others.

The following indicators have been studied:

Coloring and granulometric composition of the soil.

Soil organic matter [6].

Solid phase density is the ratio of the soil's solid phase mass (soil particles of a certain volume to the mass of the same volume of water at $4^{\circ} \mathrm{C}$ ). Solid phase density of mineral soils $2.4-2.8 \mathrm{~g} / \mathrm{cm}^{3}$. Peat $1.4-1.8 \mathrm{~g} / \mathrm{cm}^{3}$.

Soil density is the ratio of the mass of absolutely dry soil taken without violation of natural composition to its volume. It characterizes the density of soil composition and the degree of its looseness. For humus horizons, soil density is $0.9-1.3 \mathrm{~g} / \mathrm{cm}^{3}$.

Total porosity is the total volume of pores between soil particles and soil lumps expressed in $\%$ to the total soil volume. It is subdivided into capillary and non-capillary. Capillary porosity is the volume of all the smallest pores (less than $0.1 \mathrm{~mm}$ ) filled with water. Capillary pores are concentrated inside soil aggregates and retain moisture available to plants. Optimal: total porosity $-55 \%$, capillary - $30 \%$, non-capillary $-25 \%$.

Water retention soil capacity is the property to keep a certain amount of moisture from draining under the influence of capillary and sorption forces. It is characterized by values of hygroscopic moisture and moisture intensity. Moisture absorbed by the soil from the air is called hygroscopic. The highest amount of vapour water can be absorbed by the soil if the air 
saturation with water vapors is $100 \%$. This value is called maximum hygroscopicity. Hygroscopic water is not available for plants.

GOST 26205-91 Soils. Determination of mobile compounds of phosphorus and potassium by Machigin method in modification of CINAO [7].

GOST 26423-85. Soils. Determination methods of specific electrical conductivity, $\mathrm{pH}$, and dense residue of water extraction [8].

We studied the following soil characteristics in accordance with NTD [9]:

- density of the solid soil phase - by picnometer method (A.F. Vadyunina, Z.A. Korchagina, 1986);

- total porosity - by calculation method according to N.A. Kachinsky (A.F. Vadyunina, Z.A. Korchagina, 1986);

- total and hygroscopic soil moisture - thermostat-gravimetric method (A.F. Vadyunina, Z.A. Korchagina, 1986);

- granulometric composition - by Kachinskiy's "pipette method" with preliminary pyrophosphate treatment (A.F. Vadyunina, Z.A. Korchagina, 1986);

- particle-size index of structurality "Kg" according to A.F. Vadyunina (A.F. Vadyunina, Z.A. Korchagina, 1986):

for humus soils $\mathrm{Kg}=(\mathrm{S}+\mathrm{FD} / \mathrm{MD}+\mathrm{LD}) 100 \%$;

for low humus soils $\mathrm{Kg}=(\mathrm{S} / \mathrm{FD}+\mathrm{MD}+\mathrm{LD}) 100 \%$,

where $\mathrm{S}$ is the content of silt,

FD - fine dust content $(0.001-0.005 \mathrm{~mm}), \%$;

MD - medium dust content $(0.005-0.01 \mathrm{~mm}), \%$; LD - the content of large dust $(0.01-0,05$ $\mathrm{mm}), \%$;

- Structural and aggregate composition of the soil - according to the method of N.I. Savvinov — dry and wet sieving (A.F. Vadyunina, Z.A. Korchagina, 1986);

Indicators of the humus soil state:

- content of total humus (H) - according to GOST 26213-91 in soil samples from genetic horizons and directly in air-dry and water-resistant aggregates of sizes: 3-1 mm, 1-0.5 mm, 0.5-0.25 mm [10],

Agrochemical properties:

- $\mathrm{pH}$ - in 1.0 M KCl extract (GOST 26483-85) [10];

- $\mathrm{pH}$ of water extract - potentiometric method [8].

Experimental data were processed by mathematical statistics methods (Dospekhov, 1985) [12] using software tools Microsoft Office EXCEL, STATISTICA 6.0. The assessment of correlation dependence was carried out by the Chaddock scale (Kremlev A.G., 2001): 0.1 0.3 - weak; 0.3-0.5 - moderate; 0.5-0.7 - noticeable; 0.7-0.9 - high; 0.9-0.99 - very high [11].

Tests of biological samples by thermal analysis were carried out according to the method [12], [16].

Elemental analysis of soil samples and biological objects by scanning electron microscopy.

The soil analysis was carried out by the method of close infrared spectroscopy (CIRS) [15]. The SpectraStar XT infrared analyzer was used in our research.

Chemical composition of lavender oil (Lavandula angustifolia Mill.) - according to GOST ISO 3515-2017 [13].

Control of pesticide content - in accordance with GOST 32689.1-2014 [14].

\section{Results and discussion}

Two stages can be distinguished in the study:

1. Study of the ecological and chemical soils state

2. Study of chemical composition of lavender essential oil 
Study of the ecological and chemical soils state

In our work, we surveyed 21 fields, compiled field maps, conducted analysis by the following indicators:

- organic matter

- exchange potassium

- mobile phosphorus

$-\mathrm{pH}$

and the content of 17 chemical elements $(\mathrm{O}, \mathrm{Ca}, \mathrm{Si}, \mathrm{C}, \mathrm{Fe}, \mathrm{Al}, \mathrm{K}, \mathrm{Mg}, \mathrm{Ti}, \mathrm{Mn}, \mathrm{P}, \mathrm{Cl}, \mathrm{S}, \mathrm{Na}$, $\mathrm{Cu}, \mathrm{Zn}, \mathrm{F})$.

Studies on determination of mobile compounds of phosphorus and potassium, as well as determination of specific electrical conductivity, $\mathrm{pH}$ and dense residue of water extract were carried out in accordance with GOSTs [7], [8].

Healthy and high-quality soil is necessary to obtain high-quality agricultural products. The results of studies carried out in 2020 were compared with surveys performed in previous years. This made it possible to assess the impact of long-term (11 years) organic farming method on land fertility.

Based on the soil studies conducted in 2020 to determine the content of organic matter and compare them with the data of 2017 and 2019, it was established that the organic matter content has not decreased in 4 years. That is, it can be concluded that organic farming does not deplete organic matter reserves in the soil.

Determination of mobile potassium and phosphorus showed that $80 \%$ of the farm fields' soils have a very low and low content of mobile phosphorus with a sufficiently high potassium content.

Accordingly, the following recommendations were given: 1 . It is necessary to carry out a set of measures to saturate the soil with phosphorus, for example, using the saturation (sorption) of organic biomass with soluble phosphates, which is obtained after distilling lavender and sage essential oil (as organic sorbent) 2. Use the resources of fish processing enterprises of the Crimea located in Kerch, Sudak and other cities of the Crimean Peninsula 3. Use poultry manure having an acid medium reaction to transfer non-soluble phosphorus from soils to a soluble state.

Information on the fields' soil content of other chemical elements is of practical interest. The analysis showed that the soils are rich in macro- and micronutrient composition. There is a predominance of carbonates, silicates (silicon oxide). However, the composition is not balanced enough, especially for phosphorus and sulfur.

The reaction of the medium $(\mathrm{pH})$ of the farm fields is in the interval of $7.4-8.6$.

Thus, it was concluded that the fields' soils of "Efirmaslo" LLC are represented by various chemical elements and a sufficient amount of organic matter in good dynamics. To optimize the ratios and content of components in the soil, the appropriate recommended agrochemical measures should be carried out.

Based on two years of research data on the aggregate state of fields' soils on which lavender is grown for many years, the following conclusions were drawn:

1. Lavender cultivation on soils with high fertility levels as well as multiple mechanical processing help to reduce the amount of large and small fractions.

2. The proportion of medium fractions providing higher soil fertility increases by 1.4-1.6 times.

3. When growing lavender in one place for more than 25 years, the amount of large and small fractions decreases and the proportion of medium fractions increases, which provide soil fertility and are the basis soil-absorbing complex.

These findings were confirmed by the results of thermoanalytic studies.

In order to assess the spectral characteristics of soils and compile a spectra database, the CIRS analysis method was used. 
The maximum hygroscopicity of the soil was assessed. This indicator, being especially important for arid areas, characterizes the greatest amount of vapour moisture that the soil can absorb from air saturated with water vapors. The maximum hygroscopicity of heavy soils by granulometric composition and soils with high organic matter content is higher than light soils and low organic matter soils.

The obtained results on hygroscopicity correlate with the organic matter content of the soil and aggregate soil composition by particle size in the $0-20 \mathrm{~cm}$ soil layer.

Study of chemical composition of lavender essential oil

In addition to the study of the lavender oil chemical composition, an elemental biomass analysis of the apical part of lavender plants was carried out, from which the essential oil was then obtained. The results were obtained in the form of microelectronic photographs and tables containing basic macro- and micronutrients. The results of elemental analysis indicate the intensive transfer of all major macro- and micronutrients from the soil in the process of plant growth and development. Therefore, the place of lavender cultivation determines the chemical composition of essential oil, its uniqueness and quality.

The content of lavender oil in raw materials depends on many factors, but on average amounts to: in fresh inflorescences $-0.8-1.6 \%$, in fresh leaves - up to $0.4 \%$, in freshly dried leaves - up to $3 \%$, in stems - up to $0.2 \%$.

The chemical composition of lavender oil (Lavandula angustifolia Mill.) must meet the requirements of GOST ISO 3515-2017 [12].

In addition, in the production of lavender essential oil, it should be borne in mind that:

- quality indicators of lavender essential oil depend on the ratio of individual oil components.

- $\quad$ the content of terpinen-4-ol below $1.6 \%$ indicates excellent oil.

- oil with a content of terpinen-4-ol in the range of $1.6-2.4 \%$ deserves a good rating (4-4.5),

- $\quad$ oil with the content of this component at $2.4-5.8 \%$ is the average.

- $\quad$ oil with a content above $5.8 \%$ is given the lowest score by perfume indicators (2).

In the composition of lavender essential oil, there are up to 53 chemical components giving uniqueness to this product.

The main component of the oil is the esters of L-linalool alcohol and acids (acetic, oleic, valeric and capronic), as well as free linalool. Flowers also contain tannins (up to $12 \%$ ), bitters and resins, ursolic acid, coumarin, herniarin, anthocyanins, waxes and mineral salts. Coumarin and herniarine are distilled together with essential oil in the hydrodistillation process. After essential oil distillation, tricyclic diterpene alcohol is released from lavender waste.

One of the most important chemical components in lavender essential oil is linalyl acetate. If its content is around $50 \%$, then this oil is used for perfume purposes; for water and colognes - $40 \%$, for soap - $30 \%$.

Linalool is used in the preparation of perfume compositions, fragrances for soap and cosmetic products, as raw materials to produce citral, linalyl acetate and other fragrant substances, as well as some medicines.

Linalyl acetate (an ester of linalool and acetic acid with the smell of lily of the valley) is produced from linalool. Linalool and its ether are used to compile perfume compositions, fragrances for soap and cosmetic products.

Shampoos, conditioners, soap, detergents contain linalool. However, it can cause allergies and eczema in more than $5 \%$ of people.

Chemical analysis of essential oil was carried out by chromatographic method on 60 indicators of 2019 and 2020 samples obtained by traditional and organic methods.

Oil grown in the traditional way showed increased concentrations of 1.8 -cineol and camphor (over $5-8 \%$, each), which seriously reduces the commercial value of the product. 
To improve the quality of lavender essential oil, it is recommended to deterpenize it using the process of light fractions' vacuum distillation of terpene hydrocarbons. The oil quality will be higher if the concentration of lavandulyl acetate and octanon-3 increases in it.

Results of conducted studies on the chemical composition of the organic lavender essential oil produced in 2019 and 2020 and comparison with the lavender essential oil indicators produced since 2013 confirm its high quality and compliance with the requirements of the standard.

The study shows that to assess the quality of agricultural products and confirm its status as "Organic", it is necessary to analyze physico-chemical indicators not only of the product, but also other objects of the organic production system (soil, plants). An agricultural enterprise can be considered organic and fulfilling its functions in full only by proven analyses of long-term soil fertility and sufficiency and balance of all necessary compounds; such functions are production of high-quality safe products and preservation of ecological well-being of their territories.

During the study, the following observation became obvious - for the quality control system of agricultural products to work everywhere, it is necessary that the farms' specialists understand the purpose of physico-chemical methods of analysis, were able to interpret their results and to correct the applied agrotechnologies on their basis. In addition, specialists of research laboratories must possess the most modern methods of chemical, microbiological and physico-chemical analysis. This is the target of the educational program of training masters under the program "Agroecological management, chemical-toxicological, microbiological analysis and evaluation of agrosphere objects" directions "Agrochemistry and agrosoil science", implemented in RSAU-MAA named after K.A. Timiryazev for more than 10 years.

\section{Conclusion}

Thus, conducting organic products research according to the proposed "soil-plantproduction" scheme gives an objective assessment and real proof of the products' quality, its efficiency, adequacy of macro-, micronutrients and certain compounds, absence of pesticides, heavy metals, and other toxicants.

Certification of organic farming gives only a guarantee that the products were actually produced using the organic farming technology, but the manufacturer should be interested in a more complete survey of their own economy. It is such a survey that will help them to position, brand products according to quantitative chemical characteristics, manage the production process, guarantee the absence of falsification.

Modern organic farming is aimed at taking care of the ecological well-being of their territories, which involves constant monitoring to assess the balance of the soil's nutritional elements, changes in humus content, mobile forms of potassium, phosphorus, nitrogen, sulfur, other macro- and micronutrients, quality, and quantity of soil biota. Such diagnostics is required to develop a digital model for the management of physiological and biochemical processes in organic agriculture to produce high-quality organic products and preserve soil fertility.

Modern organic agriculture is a high-tech production that requires qualified specialists for its realization, including in the field of product quality control and environmental monitoring.

High quality healthy products and the ecological well-being of land are among the major wealth on our planet. Effective implementation of organic farming is possible when using modern methods of agrosphere objects monitoring (soil, water sources, plants, agricultural products) and based on the obtained scientific data on the definition of land use strategies and technologies. 


\section{References}

1. M.V. Grigoryeva, N.L. Bagnavets, S.L. Belopukhov, Agroengineering 2 (96), 64-69 (2020)

2. M.V. Grigoryeva, S.L. Belopukhov, History and pedagogics of natural science 2, 5-8 (2020)

3. M.V. Grigorieva, S.L Belopukhov, In the collection: Current state and priority directions of agrarian economy development and education, Mat. of intern. sci.-pract. conf. Persianovsky, 26-30 (2020)

4. Overview of the global cosmetics market, https://cosmetology-info.ru/7740/newsObzor-mirovogo-rynka-kosmetiki-v-2018-g-Luchshiy-god-v-istorii-mirovogo-rynkakrasoty-za-poslednie/htm

5. Successful experience of organic farming "Efirmaslo" LLC, http://agbz.ru/articles/oprovergaya-stereotipyi--uspeshnyiy-opyit-organicheskogozemledeliya-ooo--efirmaslo---kryim (access date 10.09.2019)

6. GOST 26213-91, Soils, Methods of organic matter determination.

7. GOST 26205-91, Soils, Determination of mobile compounds of phosphorus and potassium by Machigin method in CINAO modification.

8. GOST 26423-85, Soils, Determination methods of specific electrical conductivity, $\mathrm{pH}$ and dense residue of water extraction.

9. A.F. Vadyunina, Z.A. Korchagina, Methods of study of physical soil properties, 416 (1986)

10. GOST 26483-85, Soils, Preparation of salt extract and determination of its $\mathrm{pH}$ according to the method of CINAO.

11. A.G. Kremlev Mathematics. Section Statistics, 140 (2001)

12. S.L. Belopukhov, T.V. Shnei, I.I. Dmitrevskaya, Methodical instructions for testing biological samples by thermal analysis 87 (2014)

13. GOST ISO 3515-2017, Lavender essential oil (Lavandula angustifolia Mill.) Technical conditions.

14. GOST 32689.1-2014, Products of vegetable origin food, Multimethods for gaschromatographic determination of pesticide residues, Part 1. General provisions

15. S.L. Belopukhov, I.I. Dmitrievskaya, E.A. Grishina, Yu.V. Kulemkin, S.V. Bukina, Journal of Higher Educational Institutions. Textile Industry Technology, 4 (370), 115118 (2017)

16. S.L. Belopukhov, S.E. Starykh, A.N. Kupriyanov, M.V. Grigorieva, Environmental engineering, 3, 36-45 (2020) 